\title{
An Investigation of Shorting Pin Effects on Circular Disc Microstrip Antennas
}

\author{
Dilek Uzer", Seyfettin Sinan Gultekin
}

\author{
Accepted $19^{\text {th }}$ June 2015
}

DOI: 10.18100/ijamec.39970

\begin{abstract}
In this study, shorting pin addition, one of the common bandwidth enhancement techniques, is performed on traditional circular disc microstrip antennas that have three different dielectric substrate thicknesses and designed in three different resonant frequencies. Numbers of added shorting pins and positions of these pins are changed in every step, systematically and different pin combinations are tried for three antennas that design parameters are present in literature. Later, optimal pin combinations that give the intended resonant frequencies and the largest bandwidths are determined. For these optimal combinations, by keeping the resonant frequencies constant, the bandwidths of the antennas are increased to \%1.440, \%2.780 and \% 6.024, respectively. Compared to measurement results in the literature, for bandwidths, significant improvements are obtained. At the same time, it is observed that the technique of shorting pin addition increases the bandwidths in higher percentages on thicker microstrip antennas. For three antennas, it is seen that all pin combinations give similar resonant frequency variations depended on pin positions.
\end{abstract}

\section{Keywords: Circular microstrip antenna, shorting pin, bandwidth enhancement, HFSS simulation, optimization}

\section{Introduction}

In current practice, microstrip antennas are often preferred because of their specifications like small dimensions, easily mounted, simple manufacturing techniques, exc. but they have still narrow bandwidth against other antenna types. For the purpose of bandwidth enhancement, there are lots of studies and trying techniques in literature [1-5]. The most popular bandwidth enhancement techniques from literature are slots on patches [6], suitable dielectric substrate selection [6], different patch shapes $[5,6]$, shorting pin addition $[5,6]$ and compact designs that use some of these techniques at the same antenna, together [5,6]. Adding shorting pin, which is the popular one of these techniques and this technique, has a little known, bandwidth enhancement effect on microstrip patch antennas [1, 6]. Shorting pins are effective for bandwidth enhancement on quarter wave and regular patches. It is commonly known that shorting pin usage aims to reduce the patch size; also, this technique can be used for obtaining larger bandwidths $[2,5]$. In this study, size reduction property of shorting pins is not taken into account but focused on only the antenna bandwidth optimization.

Adding shorting pin on circular patch antenna leads the traditional antenna with the same size to resonate on a lower frequency. In order to obtain a good impedance matching, position of the shorting pin must be chosen closer to the feed point of the antenna. Otherwise, input impedance will increase rapidly [3].A shorting pin can act like the feed line of the microstrip antenna. In this case, it can be assumed that the pin delivers zero power to the antenna but in the $\mathrm{GHz}$ range, for high frequency patches, an inductance appears between pin, patch and dielectric substrate. In addition, if the height of the shorting pin is chosen a bit shorter, at an upper level in the substrate, instead of extending from patch surface to ground plane, this pin will generate a capacity. This generated capacity value can be evaluated as a new design parameter according to the simple patch. Thus, by providing isolation and changing the pin positions, antenna performance can be improved with an enhanced bandwidth. Input impedance of the shorted patch antenna depends on positions of feed line and shorting pin [7]. It Electrical and Electronics Engineering Department, Engineering Faculty, Selcuk University, Campus, 42031, Konya/Turkey

*Corresponding Author: Email: dilek_uzer@selcuk.edu.tr is known that all relative patch dimensions are effective on impedance behaviour [8].Besides; resonant frequency of the microstrip antenna can be controlled by changing the pin numbers and positions [9, 10]. Hereby, it can be said that resonant frequency is strongly related with the shorting pin position $[10,11]$.Starting from these shorting pin effects on microstrip patch antennas [3-6], in this study, adding shorting pins with different numbers and different positions on traditional circular disc microstrip patch antennas, simulation of these antennas performed by using HFSS v14 [12].Antenna bandwidths improved significantly against to the measured bandwidth values of the antennas from [2]. In addition, designed resonant frequency values of these antennas were preserved. Therefore, for some pin added designs, patch radii were modified in $0.1 \mathrm{~mm}$ range.

\section{Antenna Design}

Circular disc microstrip patch antennas, used in this study, were designed on Rogers Duroid 5870 substrate, which has a permittivity of 2.32 and three different thicknesses as $0.8 \mathrm{~mm}$, $1.59 \mathrm{~mm}$ and $3.18 \mathrm{~mm}$, respectively. Antenna parameters for three different dielectric thicknesses were taken from [2]. For running simulations in HFSS ANSYS Software, finite ground plane dimensions were optimized in [5] for all three antennas. In the studies, by using HFSS software, simulations of simple antenna and antennas with shorting pins were performed. In Table 1; resonant frequencies, measured bandwidths, and design parameters of the simple microstrip antennas from [2] were given. Circular disc microstrip antenna with shorting pin was shown in Figure 1. Here, $\mathrm{k}$ is the distance of the shorting pin to the patch centre.

Table 1.Antenna parameters from [2]

\begin{tabular}{ccccccccc}
\hline $\mathrm{a}$ & $\mathrm{x}_{\mathrm{f}}$ & $\mathrm{h}$ & $\varepsilon_{\mathrm{r}}$ & $\mathrm{f}_{\text {rcal. }}$ & $\Delta \mathrm{f}_{\text {rcal. }}$ & $\mathrm{f}_{\text {rmeas. }}$ & $\Delta \mathrm{f}_{\text {rmeas. }}$ & $\mathrm{BW}_{\text {meas. }}$ \\
\hline 68 & 65 & 0.8 & 2.32 & 840 & & 835 & & 1.2 \\
68 & 65 & 1.59 & 2.32 & 833 & & 829 & 6 & 1.6 \\
68 & 65 & 3.18 & 2.32 & 821 & & 815 & & 2.1 \\
\hline
\end{tabular}

- $\quad \mathrm{a}, \mathrm{x}_{\mathrm{f}}$ and $\mathrm{h}$; in $\mathrm{mm}$ 
- $\mathrm{f}_{\text {rcal. }}, \Delta \mathrm{f}_{\text {rcal. }}, \mathrm{f}_{\text {rmeas. }}$ and $\Delta \mathrm{f}_{\text {rmeas.; }}$; in $\mathrm{MHz}$

- $\mathrm{BW}_{\text {meas. }}$ in $\%$

Where;

a: Antenna radius

$\mathrm{x}_{\mathrm{f}}$ : Coax-fed point

h: Dielectric thickness

$\varepsilon_{\mathrm{r}}$ : Dielectric permittivity

$\mathrm{f}_{\text {rcal.: }}$ Calculated resonant frequency

$\Delta \mathrm{f}_{\text {rcal }}$ : Difference calculated between the resonant frequencies corresponding to three thicknesses

$\mathrm{f}_{\text {rmeas. }}$ : Measured resonant frequency

$\Delta f_{\text {rmeas: }}$ : Difference measured between the resonant frequencies corresponding to three thicknesses

$\mathrm{BW}_{\text {meas: }}$ : Measured bandwidth

In the first section of the study, one copper shorting pin that has a radius of $0.5 \mathrm{~mm}$ was added on the certainly opposite of the feed point. The parameter $\mathrm{k}$, represents the pin point, was swept by 1 $\mathrm{mm}$ steps, from one edge to the next, along the $136 \mathrm{~mm}$ - diameter of the patch. Then, as can be seen from Table 2, two pins were placed perpendicular to the feed point and their $\mathrm{k}$ parameters were swept again in the second part. In the third part, three pins were added on the patches positioned like in the first and second parts, together and simulations were repeated for the same steps. So, the first section was completed. In the second section, two shorting pins were added in line between $1 \mathrm{~mm}$ with them and this part was repeated for the third part. This section was not done for the second part, because, although similar results were taken from the first and the third parts in the first section, there were no meaningful results of resonant frequency and bandwidth variations against $\mathrm{k}$ values for the second part of the first section. For all other pin combinations, resonant frequency and bandwidth variations with $\mathrm{k}$ values are compatible with together, so it was concluded that if $\mathrm{k}$ position were chosen closer to the patch centre, while the resonant frequency is coming near to the design frequency, the bandwidth value would increase. The graphics of these variations for all three antennas are given in Figure 2, for all different pin positions and numbers.

In the last section, two shorting pins were placed at a position facing the feed point where pins have a $135^{\circ}$ with the feed line and a $90^{\circ}$ with together, seen from Table 2 . Then the sweep by $\mathrm{k}$ values was repeated.

In all sections, after determining the optimum $\mathrm{k}$ values for pin combinations, these values were kept constant and small optimizations were done on the patch radii for obtaining the design frequencies. While evaluating simulation results, the errors because of pin intersections with the coaxial feed or the other shorting pins were not taken into account and not put in result tables.

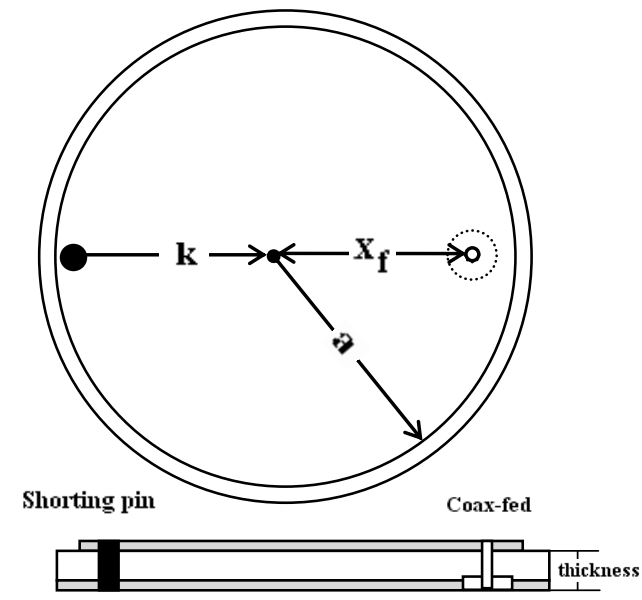

Figure1.Circular disc antenna design with shorting pin

\section{Analysis and Results}

For all three microstrip antennas, k-resonant frequency and kbandwidth variation graphics for different pin combinations obtained from simulations were given in Figure 3 with the literature results. It can seen from these graphics, if $\mathrm{k}$, the pin position, is chosen closer to the patch centre, the patch impedance is effected from the position of the shorting pin, so the resonant frequency can be obtained so close to the design frequency value because of providing the impedance matching effective, then the bandwidth is increased. For Patch no1 and Patch no2, "2 pins with $90^{\circ}$ " combination gave the best bandwidth results, as $\% 1.440$ and \%2.780, respectively. For Patch no3, "1x2 pins inline" combination gave a bandwidth value as \% 6.024. All the antennas needed radius optimization to obtain the design resonant frequencies. The other simulation results can be seen from Table 2. In Table 2, bold lines show the best bandwidth results for every microstrip patch with the pin combination. After trials in simulations, for all three different antenna substrate thicknesses, the two pin opposing positioning did not give any significant variations in resonant frequency and bandwidth values.

As can be seen from Figure 3, the largest proportional increase was obtained for Patch no3, which has the thickest dielectric substrate. Thus, it can be said that the proportional increase in the bandwidth is inversely with $\mathrm{f}_{\mathrm{r}} / \mathrm{h}$ proportion. Hereby, it is concluded that the shorting pin addition technique can be used more effectively on thick microstrip antennas. To support this, it is planning to study using this bandwidth enhancement technique on many thicker microstrip antennas with different dielectric substrate specifications.

\section{Conclusion}

In this study, it is aimed to enhance the bandwidth of circular disc microstrip patch antennas available in the literature by adding shorting pins with different numbers and positions on them. While increasing their bandwidths, it is made a point of keeping the original resonant frequencies, which the antennas were designed. It is seen that the distance to the centre of the patch and the feed line position must be taken into account while the pin position, $\mathrm{k}$, is determined. In addition, it is observed that this technique is more efficient on thick microstrip patch antennas. As a result of this study, it is concluded that a bandwidth enhancement can be easily obtained by adding shorting pins with different combinations on even microstrip antennas previously produced, without compromising the design frequency.

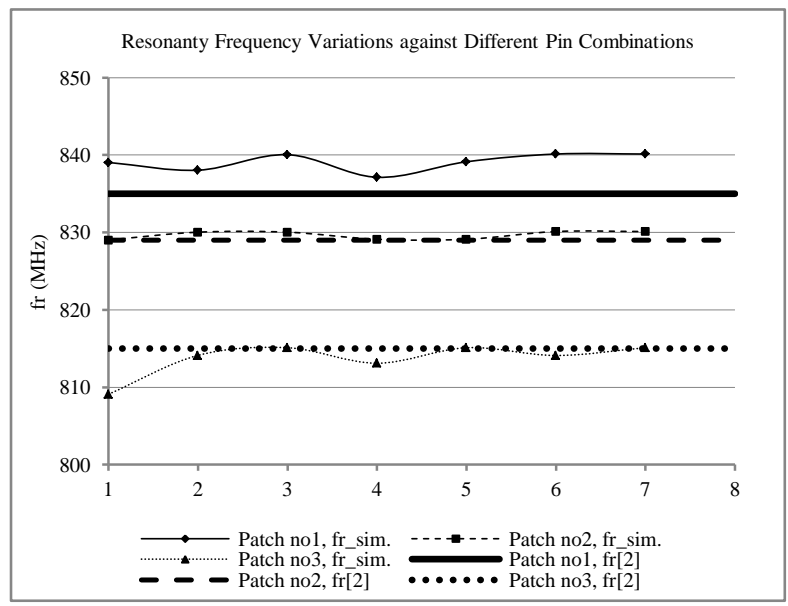

(a) Resonant Frequency Variations 


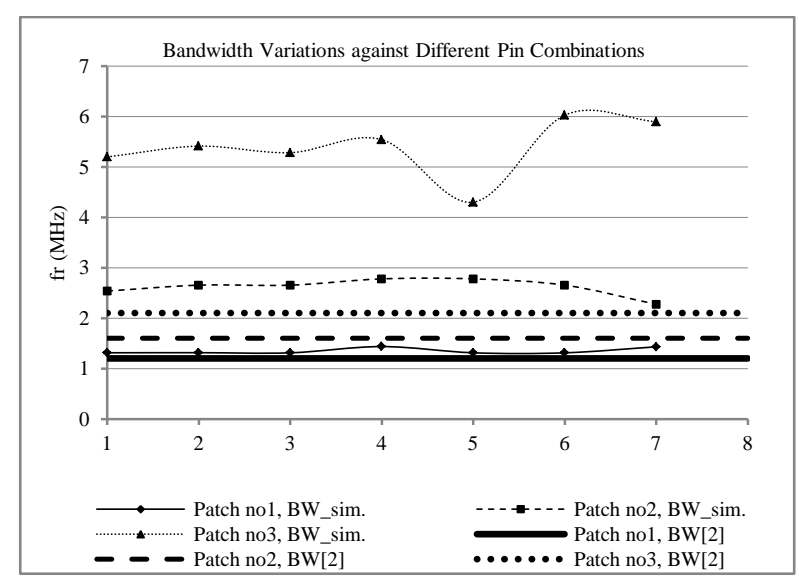

(b) Bandwidth Variations

Figure3.Resonant Frequency and Bandwidth Variations for Different Pin Combinations for Three Microstrip Antennas

\section{Acknowledgements}

This study is supported by the Unit of the Scientific Research Projects of Selcuk University in Turkey.

\section{References}

[1] BahlI. J. and Bhartia P. Microstrip Antennas. Artech House, 1980, chp. 3.

[2] Dahele J.S., and Lee K.F. Effect of Substrate Thickness on the Performance of a Circular-Disk Microstrip Antenna, IEEE Transactions on Antennas and Propagation, Vol. AP-

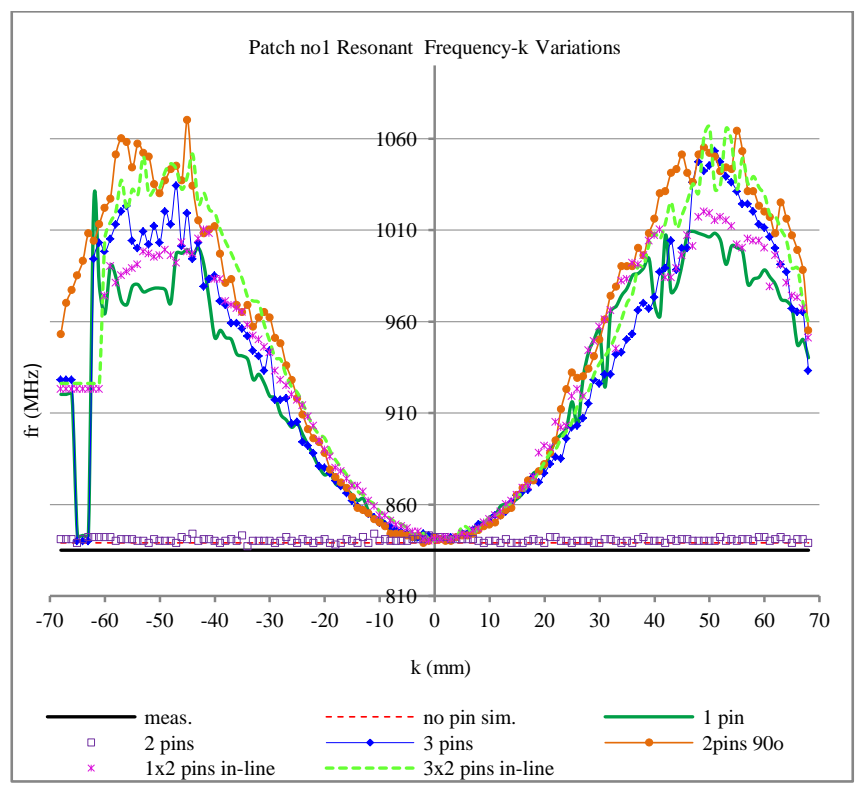

31, No. 2, , pp:358-360, March 1983.

[3] Kumar G. and Ray K.P. Broadband Microstrip Antennas, Artech House, Boston, London, 2003.

[4] Koçer D. Simulation of Circular and Rectangular Microstrip Antennas and Determination of Their Resonant Frequencies by Artificial Neural Networks, M.S. Thesis, Dept. Elect. and Electro. Eng., Graduate School of Natural Sciences, Selcuk University, Konya, Turkey, 2009.

[5] Uzer D. Investigation on Favourable Methods for Wideband Microstrip Patch Antenna Designs, PhD. Thesis, Dept. Elect. and Electro. Eng., Graduate School of Natural Sciences, Selcuk University, Konya, Turkey, (continuing).

[6] Wong K.L. Compact and Broadband Microstrip Antennas, Wiley Inc. 2002.

[7] Wong K. L., Tang C. L., and Chen H. T. A Compact Meandered Circular Microstrip Antenna with a Shorting Pin, Microwave Opt. Technol. Lett. 15, 147-149, June 20, 1997.

[8] Dey S. and Mittra R. Compact Microstrip Patch Antenna Microwave Opt. Technol. Lett.13, 12-14, Sept. 1996.

[9] Sharma A. and Singh G. Design of Single Pin Shorted Three-Dielectric-Layered Substrates Rectangular Patch Microstrip Antenna for Communication Systems, Progress In Electromagnetics Research Letters, Vol. 2, 157-165, 2008.

[10] Information and Communication Technologies, 2010 ICT India September, Proceedings, Springer.

[11] Wong K. L. and W. Chen S. Compact Microstrip Antenna with Dual-Frequency Operation, Electron.Lett.33, 646-647, April 10, 1997.

[12] HFSS v14, www.ansys.com/HFSS

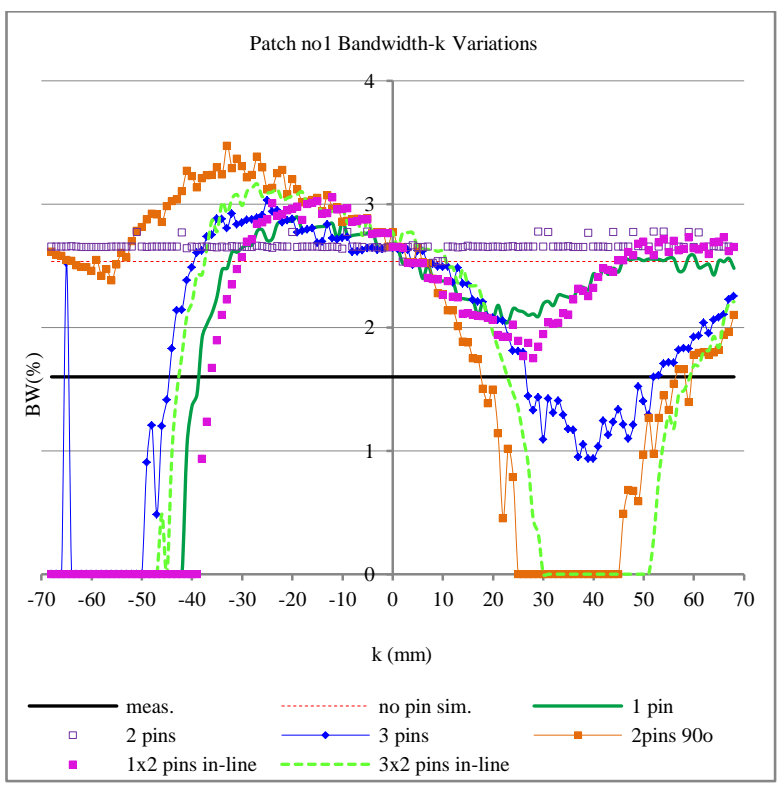



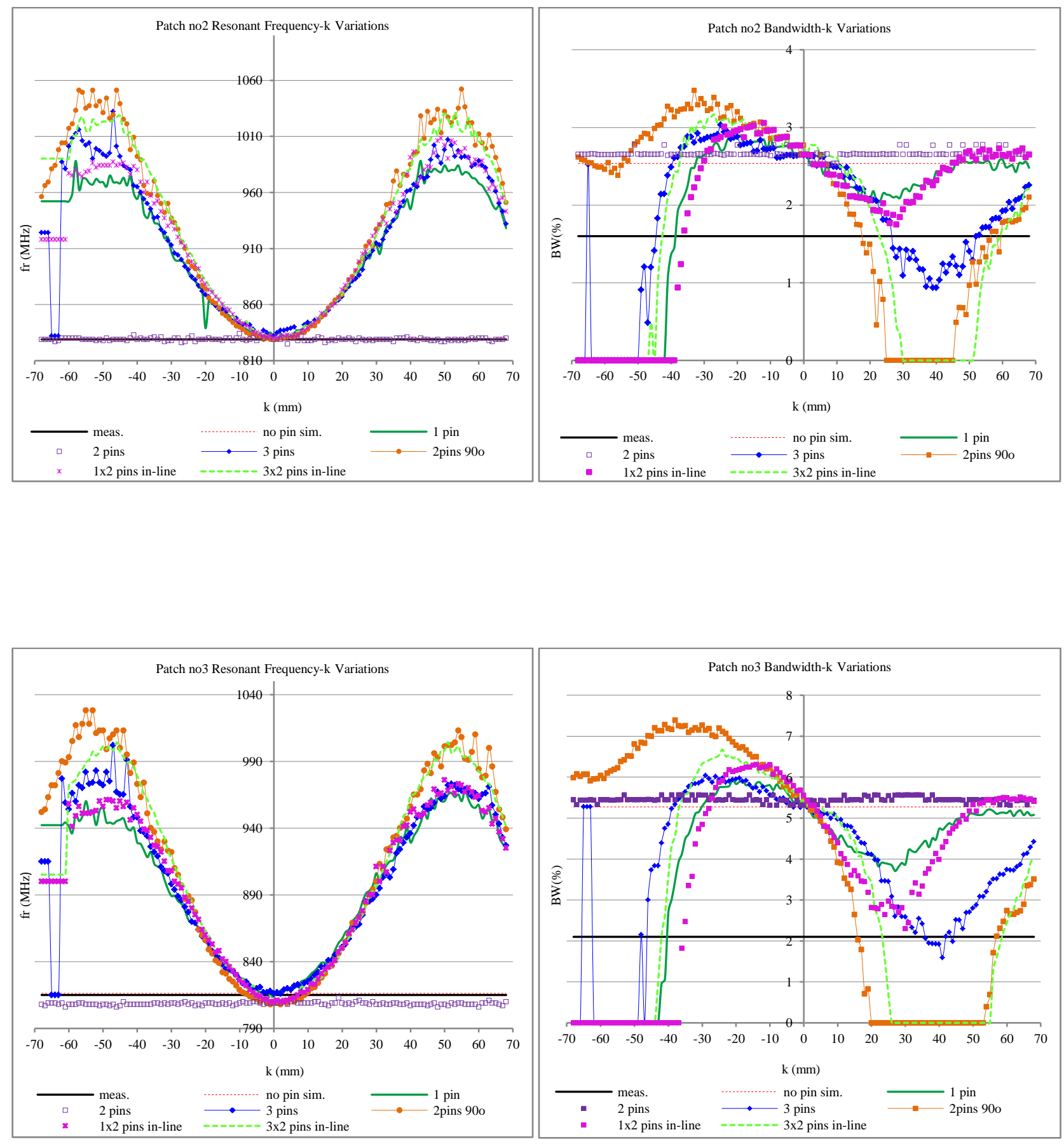

Figure2. Resonant Frequency and Bandwidth against k Variations

a) Patch no1f $f_{r}$, b) Patch no1 BW, c) Patch no2 $f_{r} d$ ) Patch no2 BW, e) Patch no3 $f_{r}$, f) Patch no3 BW 
Table2. Best simulation results for pin added circular disc microstrip antennas

\begin{tabular}{|c|c|c|c|c|c|c|c|c|c|c|c|}
\hline Pin combination & Pin topology & $\begin{array}{c}\text { Radius } \\
(\mathrm{mm})\end{array}$ & $\begin{array}{c}\mathrm{k} \\
(\mathrm{mm})\end{array}$ & $\begin{array}{c}\mathrm{h} \\
(\mathrm{mm})\end{array}$ & $\begin{array}{c}\mathrm{f}_{\mathrm{r}} \\
(\mathrm{MHz})\end{array}$ & $\begin{array}{l}\mathrm{BW} \\
(\%)\end{array}$ & $\begin{array}{l}Z_{\text {in }} \\
(\Omega)\end{array}$ & $\begin{array}{l}\text { Gain } \\
(\mathrm{dB})\end{array}$ & Directivity & $\begin{array}{c}\text { Efficiency } \\
(\%)\end{array}$ & $\begin{array}{c}\mathrm{S}_{11} \text { response } \\
(\mathrm{dB})\end{array}$ \\
\hline \multirow[b]{3}{*}{ No pin } & & 68.0 & $*$ & 0.80 & 839.039 & 1.312 & 65.558 & 0.623 & 0.775 & 0.804 & -19.766 \\
\hline & & 68.0 & $*$ & 1.59 & 829.029 & 2.536 & 62.507 & 0.652 & 0.710 & 0.919 & -22.998 \\
\hline & & 68.0 & $*$ & 3.18 & 816.211 & 5.272 & 58.600 & 0.540 & 0.563 & 0.959 & -16.724 \\
\hline \multirow{3}{*}{1 pin } & & 68.0 & 9 & 0.80 & 838.038 & 1.314 & 56.412 & 0.654 & 0.848 & 0.770 & -27.134 \\
\hline & & 68.0 & -3 & 1.59 & 830.030 & 2.653 & 67.843 & 0.646 & 0.724 & 0.892 & -30.756 \\
\hline & & 68.0 & -2 & 3.18 & 814.114 & 5.410 & 65.100 & 0.584 & 0.621 & 0.940 & -24.221 \\
\hline \multirow{3}{*}{$\begin{array}{c}1 \text { pin } \\
\text { radius } \\
\text { optimization }\end{array}$} & & 69.0 & 9 & 0.80 & 836.036 & 1.197 & 72.232 & 0.654 & 0.820 & 0.797 & -27.892 \\
\hline & & 68.2 & -3 & 1.59 & 829.029 & 2.656 & 65.224 & 0.661 & 0.770 & 0.859 & -25.870 \\
\hline & & 68.0 & -2 & 3.18 & 814.114 & 5.410 & 65.100 & 0.584 & 0.621 & 0.940 & -24.221 \\
\hline \multirow{3}{*}{2 pins } & & 68.0 & -34 & 0.80 & 840.040 & 1.311 & 68.745 & 0.646 & 0.763 & 0.847 & -23.353 \\
\hline & & 68.0 & 44 & 1.59 & 830.030 & 2.653 & 62.518 & 0.654 & 0.701 & 0.933 & -25.299 \\
\hline & & 68.0 & 19 & 3.18 & 815.105 & 5.280 & 53.123 & 0.533 & 0.562 & 0.950 & -17.904 \\
\hline \multirow{3}{*}{$\begin{array}{c}2 \text { pins } \\
\text { radius } \\
\text { optimization }\end{array}$} & & 68.4 & -34 & 0.80 & 835.123 & 1.318 & 68.087 & 0.661 & 0.770 & 0.859 & -22.343 \\
\hline & & 68.0 & 44 & 1.59 & 830.030 & 2.653 & 62.518 & 0.654 & 0.701 & 0.933 & -25.299 \\
\hline & & 67.6 & 19 & 3.18 & 815.105 & 5.649 & 60.308 & 0.538 & 0.567 & 0.947 & -18.988 \\
\hline \multirow{3}{*}{3 pins } & & 68.0 & -65 & 0.80 & 837.125 & 1.435 & 75.301 & 0.654 & 0.784 & 0.834 & -31.210 \\
\hline & & 68.0 & -1 & 1.59 & 829.117 & 2.777 & 70.973 & 0.683 & 0.725 & 0.942 & -30.303 \\
\hline & & 68.0 & -65 & 3.18 & 813.103 & 5.539 & 66.176 & 0.592 & 0.629 & 0.941 & -22.759 \\
\hline \multirow{3}{*}{$\begin{array}{c}3 \text { pins } \\
\text { radius } \\
\text { optimization }\end{array}$} & & 68.9 & -65 & 0.80 & 833.033 & 1.322 & 48.102 & 0.644 & 0.754 & 0.853 & -12.150 \\
\hline & & 68.4 & -1 & 1.59 & 828.028 & 2.660 & 59.890 & 0.674 & 0.722 & 0.933 & -20.073 \\
\hline & & 68.2 & -65 & 3.18 & 815.105 & 5.403 & 64.715 & 0.593 & 0.632 & 0.938 & -23.585 \\
\hline \multirow{4}{*}{2 pins $90^{\circ}$} & & 68.0 & -2 & 0.80 & 839.126 & 1.312 & 67.279 & 0.655 & 0.768 & 0.852 & -25.986 \\
\hline & & 68.0 & -3 & 1.59 & 829.117 & 2.777 & 67.155 & 0.651 & 0.700 & 0.929 & -27.359 \\
\hline & & 68.0 & 9 & 3.18 & 815.105 & 4.298 & 62.341 & 0.544 & 0.565 & 0.963 & -20.741 \\
\hline & & 68.0 & -7 & 3.18 & 814.104 & 6.024 & 54.362 & 0.524 & 0.556 & 0.943 & -13.689 \\
\hline \multirow{4}{*}{$\begin{array}{l}2 \text { pins } 90^{\circ} \\
\text { radius } \\
\text { optimization }\end{array}$} & & 68.6 & -2 & 0.80 & 834.122 & 1.440 & 63.933 & 0.631 & 0.753 & 0.838 & -24.446 \\
\hline & & 68.0 & -3 & 1.59 & 829.117 & 2.777 & 67.155 & 0.651 & 0.700 & 0.929 & -27.359 \\
\hline & & 68.0 & 9 & 3.18 & 815.105 & 4.298 & 62.341 & 0.544 & 0.565 & 0.963 & -20.741 \\
\hline & & 67.9 & -7 & 3.18 & 814.104 & 6.024 & 63.406 & 0.535 & 0.560 & 0.954 & -20.645 \\
\hline \multirow{3}{*}{$\begin{array}{l}1 \times 2 \text { pins } \\
\text { in-line }\end{array}$} & & 68.0 & -1 & 0.80 & 840.127 & 1.311 & 66.597 & 0.647 & 0.770 & 0.840 & -24.927 \\
\hline & & 68.0 & 0 & 1.59 & 830.118 & 2.653 & 66.134 & 0.652 & 0.709 & 0.919 & -26.094 \\
\hline & & 68.0 & -5 & 3.18 & 815.105 & 5.894 & 62.642 & 0.540 & 0.565 & 0.955 & -20.023 \\
\hline \multirow{3}{*}{$\begin{array}{l}1 \times 2 \text { pins } \\
\text { in-line } \\
\text { radius } \\
\text { optimization }\end{array}$} & & 68.6 & -1 & 0.80 & 835.123 & 1.438 & 64.736 & 0.656 & 0.766 & 0.857 & -25.878 \\
\hline & & 68.1 & $\mathbf{0}$ & 1.59 & 828.116 & 2.780 & $\begin{array}{l}65.909 \\
\end{array}$ & 0.646 & 0.709 & 0.910 & -25.424 \\
\hline & & 68.0 & -5 & 3.18 & 815.105 & 5.894 & 62.642 & 0.540 & 0.565 & 0.955 & -20.023 \\
\hline \multirow{3}{*}{$\begin{array}{l}3 \times 2 \text { pins } \\
\text { in-line }\end{array}$} & & 68.0 & 0 & 0.80 & 840.127 & 1.430 & 65.754 & 0.654 & 0.768 & 0.850 & -25.421 \\
\hline & & 68.0 & 0 & 1.59 & 830.118 & 2.273 & 66.481 & 0.659 & 0.709 & 0.928 & -26.214 \\
\hline & & 68.0 & -4 & 3.18 & 815.105 & 5.649 & 60.188 & 0.540 & 0.564 & 0.956 & -18.564 \\
\hline \multirow{3}{*}{$\begin{array}{l}3 \times 2 \text { pins } \\
\text { in-line } \\
\text { radius } \\
\text { optimization }\end{array}$} & & 68.5 & 0 & 0.80 & 835.123 & 1.438 & 63.331 & 0.651 & 0.774 & 0.841 & -24.219 \\
\hline & & 68.1 & 0 & 1.59 & 841.128 & 2.653 & 66.140 & 0.665 & 0.713 & 0.932 & -26.422 \\
\hline & & 68.0 & -4 & 3.18 & 815.105 & 5.649 & 60.188 & 0.540 & 0.564 & 0.956 & -18.564 \\
\hline
\end{tabular}

